\title{
Theaflavins, Thearubigins, and Theasinensins
}

\author{
Wojciech Koch
}

\section{Contents}

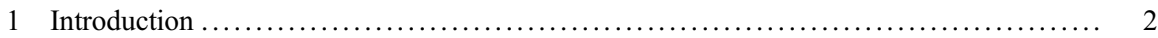

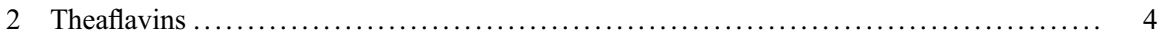

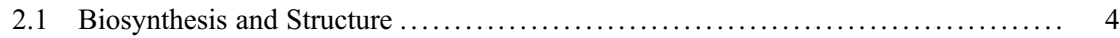

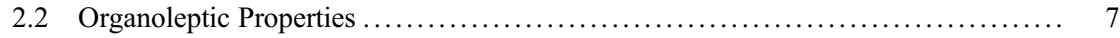

2.3 Absorption and Metabolism of Theaflavins .............................. 8

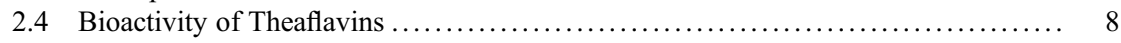

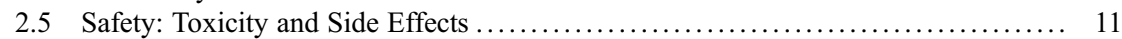

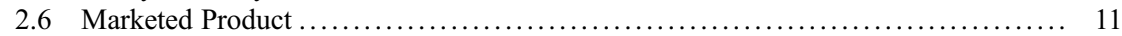

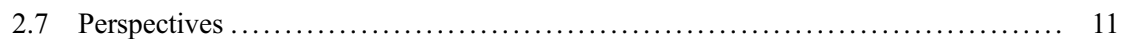

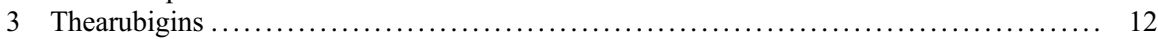

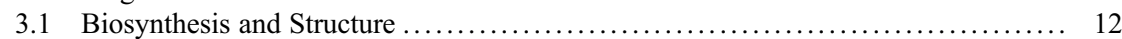

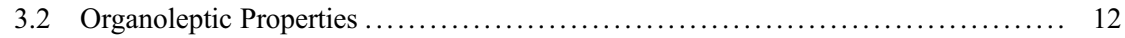

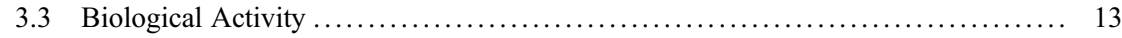

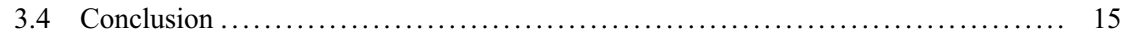

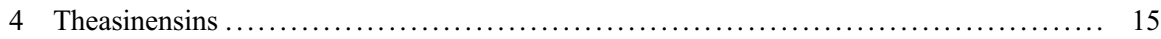

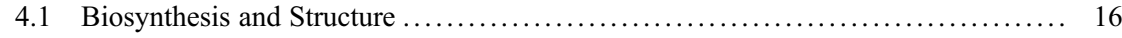

4.2 Biological Properties of Theasinensins ................................. 18

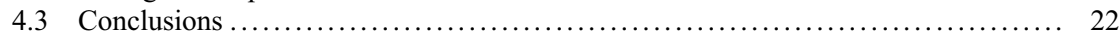

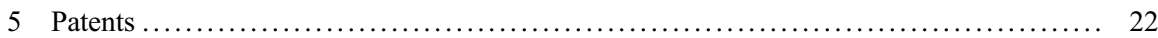

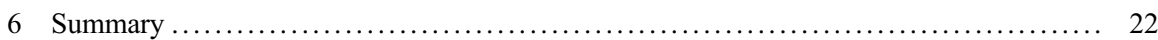

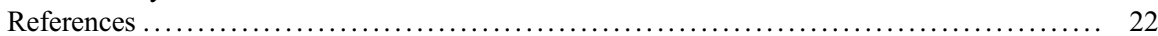

\begin{abstract}
Tea, except water, is the most widely consumed beverage across the world. It contains many active substances, among which polymeric polyphenols (theaflavins, thearubigins, and theasinensins) are dominant in fermented teas. Theaflavins and thearubigins are the major polyphenolic compounds in black
\end{abstract}

\footnotetext{
W. Koch $(\bowtie)$

Department of Food and Nutrition, Medical University of Lublin, Lublin, Poland

e-mail:kochw@interia.pl
} 
tea, whereas theasinensins are the most characteristic for oolong tea. All of these classes of polyphenols have complicated structure and complex route of synthesis, in which polyphenol oxidase is a crucial enzyme. The aim of the present chapter is to provide a summary on the current knowledge on theaflavins, thearubigins, and theasinensins associated with chemical structure, molecular action pathways, and health benefits based on the scientific evidences available on the literature.

\section{Keywords}

Black tea $\cdot$ Catechins $\cdot$ Theaflavins $\cdot$ Thearubigins $\cdot$ Theasinensins

\section{Introduction}

Tea is a very popular drink in the world, and after water, it is the most frequently consumed beverage. The annual production of tea is estimated to around 2.9 billion tons. Every day almost $70 \%$ of the global population drinks $18-20$ billion cups of tea. Camellia sinensis (L.) Kuntze belongs to the family Theaceae and is cultivated in over 45 countries from all continents, except North America and Antarctica. Subtropical and tropical climate with high precipitation and little acidic soil are the most preferable conditions for tea cultivation (Barua 2008). Young leaves, immature buds, and delicate stalks of tea bush are processed to produce tea as a food product. Taking into account the production process, tea can be divided into several types, of which green and black teas are the most popular ones. In the scientific literature, different classifications can be found; however recently Yi and co-workers (2015), based on the production process, divided tea into seven sub-types, namely, black, green, white, yellow, oolong, aged $\mathrm{Pu}$-erh, and ripened $\mathrm{Pu}$-erh. Green and white teas are non-fermented products, while the latter one is considered high-quality tea produced from young leaves and buds harvested before their maturation, mostly in spring. The tea leaf contains over 4000 active constituents. Table 1 summarizes the composition of tea according to the leaf and to the tea infusion.

Polyphenols are the main and most widely distributed secondary metabolites present in plants. They can be divided into several subclasses of which flavonoids are the most complicated and widespread in the plant kingdom (Fig. 1).

The basic structure of flavonoids, so-called flavan skeleton, consists of two aromatic rings linked by a three-carbon atom heterocyclic ring. All flavonoids contain $\mathrm{OH}$ groups in the positions 5- and 7- in the A ring and in the position 3in the $\mathrm{B}$ ring; however the differences in location and character of other $\mathrm{OH}$ groups and the presence or absence of a double bond between carbon atoms 2 and 3 in the $\mathrm{C}$ ring are the reasons for the division of this group of compounds into several subclasses: flavanones, flavonols, flavones, isoflavones, anthocyanidins, and flavan-3-ols. The latter one, also called catechins, are the main active constituents of tea. A characteristic feature of these substances is the presence of the -OH group in position 3 in the $\mathrm{C}$ ring (Fig. 2). 
Table 1 The composition of tea

\begin{tabular}{|c|c|}
\hline $\begin{array}{l}\text { Composition of fresh, unprocessed } \\
\text { leaves (dry weight) }\end{array}$ & $\begin{array}{l}\text { Composition of water infusion, prepared from fresh } \\
\text { unprocessed tea leaves (dry weight) }\end{array}$ \\
\hline Polyphenols $36 \%$ & $\begin{array}{l}\text { Polyphenols: } \\
\text { Catechins } 30 \% \\
\text { Simple polyphenols } 2 \% \\
\text { Flavonols } 2 \% \\
\text { Other polyphenols } 6 \%\end{array}$ \\
\hline Carbohydrates $25 \%$ & Carbohydrates $11 \%$ \\
\hline Proteins $15 \%$ & Proteins $6 \%$ \\
\hline Theanine $4 \%$ & Theanine $3 \%$ \\
\hline Free amino acids $1-5.5 \%$ & Free amino acids $3 \%$ \\
\hline Fats $2 \%$ & Fats 3\% \\
\hline $\begin{array}{l}\text { Alkaloids: } \\
\text { Caffeine } 3.5 \% \\
\text { Theobromine } 0.15-0,2 \% \\
\text { Theophylline } 0.02-0,04 \%\end{array}$ & $\begin{array}{l}\text { Alkaloids: } \\
\text { Caffeine 3\% } \\
\text { Other methylxanthines }<1 \%\end{array}$ \\
\hline Organic acids $1.5 \%$ & Organic acids $2 \%$ \\
\hline $\begin{array}{l}\text { Ash (inorganic compounds) } 5 \% \\
\text { Lignin } 6.5 \% \\
\text { Chlorophyll and other pigments } \\
0.5 \% \\
\text { Carotenoids and volatiles }<0.1 \%\end{array}$ & $\begin{array}{l}\text { Potassium } 5 \% \\
\text { Other inorganic compounds 5\% } \\
\text { Volatiles (traces) }\end{array}$ \\
\hline
\end{tabular}

Fig. 1 Flavan skeleton - a basic structure of flavonoids<smiles>c1ccc(C2CCc3ccccc3O2)cc1</smiles>

The major catechins present in the tea leaves, alongside with their abbreviations used in the literature, are (-)-gallocatechin (GC), (-)-epicatechin gallate (ECG), (-)-epigallocatechin (EGC), (+)-catechin (C), (-)-epicatechin (EC), (-)gallocatechin gallate (GCG), and (-)-epigallocatechin-3-gallate (EGCG). Their structures were presented below (Fig. 3).

During the fermentation, which is the main process in the production of black tea, over $75 \%$ of catechins are transformed into complicated polymers, such as theaflavins (TFs), thearubigins (TRs), and theasinensins (TSs). 


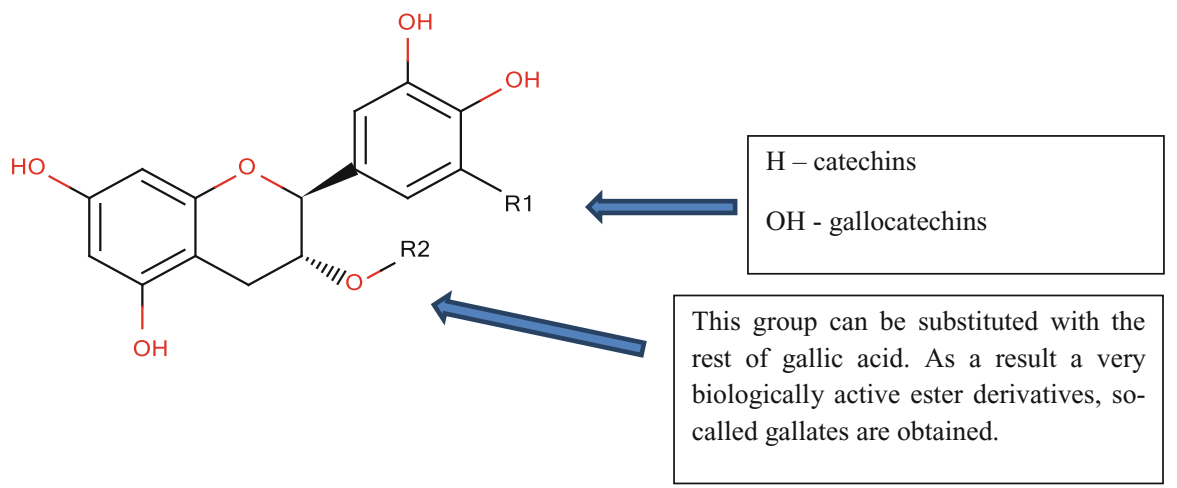

Fig. 2 The structure of flavan-3-ols

\section{Theaflavins}

\subsection{Biosynthesis and Structure}

The composition of black tea was presented in Table 2 .

Theaflavins and thearubigins are the major polyphenolic compounds in black tea. The first accounts for $2-6 \%$ of solids in the dry matter of the brew of the black tea. TFs are synthesized during the dimerization process of catechins. So far more than 25 theaflavins were found in the black tea. The main element of their structure is the seven-membered benzotropolone ring, which is formed due to the oxidation of the epigallocatechin ring $\mathrm{B}$ or epigallocatechin gallate, followed by decarboxylation and simultaneous fusion with the epicatechin ring B or epicatechin gallate (Beecher 2003). The most important theaflavins found in black tea are theaflavin $\left(\mathrm{TF}_{1}\right)$, theaflavin-3gallate $\left(\mathrm{TF}_{2} \mathrm{~A}\right)$, theaflavin-3'-gallate $\left(\mathrm{TF}_{2} \mathrm{~B}\right)$, and theaflavin-3,3'-digallate $\left(\mathrm{TF}_{3}\right)$. In literature some other signatures of $T F s$ can be found, namely, $\mathrm{TF}_{1}$ as $\mathrm{TF}, \mathrm{TF}_{2} \mathrm{~A}$ as $\mathrm{TF}_{1}$, and $\mathrm{TF}_{2} \mathrm{~B}$ as $\mathrm{TF}_{2}$. Theaflavin-3,3'-digallate is always marked as $\mathrm{TF}_{3}(\mathrm{He} 2017)$. In addition to theaflavins in tea infusions, the presence of other compounds that are derivatives of benzotropolone, among others theaflagalline or theaflavin acids, was proofed. The structures of four main TFs alongside with the basic monomers were illustrated in Fig. 4.

The relative proportion in which particular theaflavins are present in black tea was reported to be as follows: theaflavin (18\%), theaflavin-3-gallate (18\%), theaflavin-3'gallate $(20 \%)$, theaflavin-3,3'-digallate $(40 \%)$, and minor derivatives such as theaflavic acids.

The reactions of oxidation and polymerization of catechins probably occur with the participation of two enzymes: polyphenol oxidase and peroxidase. It is believed that mainly polyphenol oxidase is responsible for the oxidation of flavanols to theaflavins and thearubigins (Haslam 2003). Peroxidase activity, which catalyzes the oxidation reaction of phenols to quinones with the participation of hydrogen 


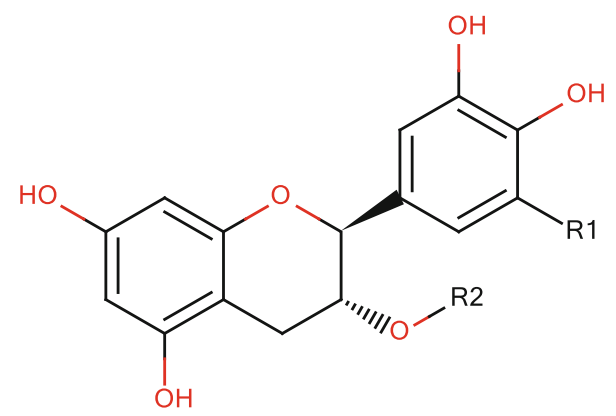

\begin{tabular}{|l|l|l|}
\hline & $\mathrm{R}_{1}$ & $\mathrm{R}_{2}$ \\
\hline (+)-catechin & $\mathrm{H}$ & $\mathrm{H}$ \\
\hline$(-)$-gallocatechin & $\mathrm{OH}$ & $\mathrm{H}$ \\
\hline (+)-catechin gallate & $\mathrm{H}$ & Gallic acid \\
\hline (-)-gallocatechin gallate & $\mathrm{OH}$ & Gallic acid \\
\hline
\end{tabular}

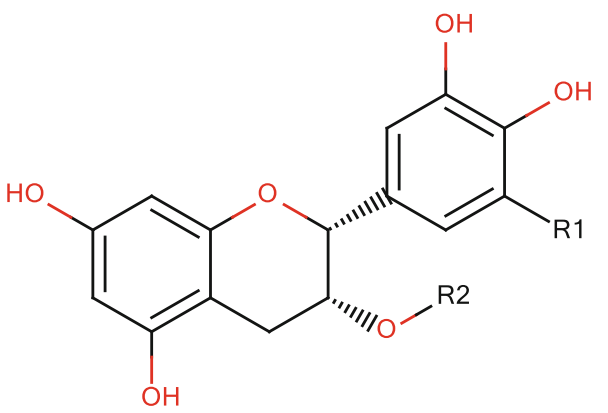

\begin{tabular}{|l|l|l|}
\hline & $\mathbf{R}_{\mathbf{1}}$ & $\mathbf{R}_{\mathbf{2}}$ \\
\hline (-)-epicatechin & $\mathrm{H}$ & $\mathrm{H}$ \\
\hline (-)-epigallocatechin & $\mathrm{OH}$ & $\mathrm{H}$ \\
\hline $\begin{array}{l}\text { (-)-epicatechin gallate } \\
\text { (-)-epigallocatechin-3- } \\
\text { gallate }\end{array}$ & $\mathrm{H}$ & Gallic acid \\
\hline
\end{tabular}

Fig. 3 Structures of the tea catechins

peroxide, has been shown to be five times higher in fresh tea leaves compared to the oxidase, and its activity increases during the production process. However, its role in 
Table 2 The composition of black tea

\begin{tabular}{l|l}
\hline Compounds & $\begin{array}{l}\text { Content (\% of dry } \\
\text { matter) }\end{array}$ \\
\hline $\begin{array}{l}\text { Polyphenols } \\
\begin{array}{l}\text { Flavonoids (mainly catechins, but also flavonols, flavones, phenolic } \\
\text { acids, and proanthocyanidins) }\end{array}\end{array}$ & 5 \\
\hline Thearubigins and theaflavins & 25 \\
\hline Proteins & 15 \\
\hline Amino acids & 4 \\
\hline Carbohydrates (including fiber) & 33 \\
\hline Fats & $2.5-7.0$ \\
\hline Alkaloids (mainly caffeine) & 4 \\
\hline Pigments (mainly chlorophyll and carotenoids) & 2 \\
\hline Volatiles & 0.1 \\
\hline Minerals & 5 \\
\hline &
\end{tabular}<smiles>[R1]C1Cc2c(O)cc(O)cc2O[C@@H]1c1cc(O)c(O)c2c(=O)c(O)cc([C@@H]3Oc4cc(O)cc(O)c4CC3[R2])cc12</smiles>

\begin{tabular}{|l|l|l|l|}
\hline & $\mathbf{R}_{1}$ & $\mathbf{R}_{\mathbf{2}}$ & Monomers \\
\hline Theaflavin $\left(\mathrm{TF}_{1}\right)$ & $\mathrm{OH}$ & $\mathrm{OH}$ & EC+EGC \\
\hline $\begin{array}{l}\text { Theaflavin-3-gallate } \\
\left(\mathrm{TF}_{2} \mathrm{~A}\right)\end{array}$ & Gallic acid & $\mathrm{OH}$ & EC+EGCG \\
\hline $\begin{array}{l}\text { Theaflavin-3'-gallate } \\
\left(\mathrm{TF}_{2} \mathrm{~B}\right)\end{array}$ & $\mathrm{OH}$ & Gallic acid & EGC+ECG \\
\hline $\begin{array}{l}\text { Theaflavin-3,3'- } \\
\text { digallate } \\
\left(\mathrm{TF}_{3}\right)\end{array}$ & Gallic acid & Gallic acid & ECG+EGCG \\
\hline
\end{tabular}

Fig. 4 Structures of tea theaflavins (Lambert and Yang 2003) 

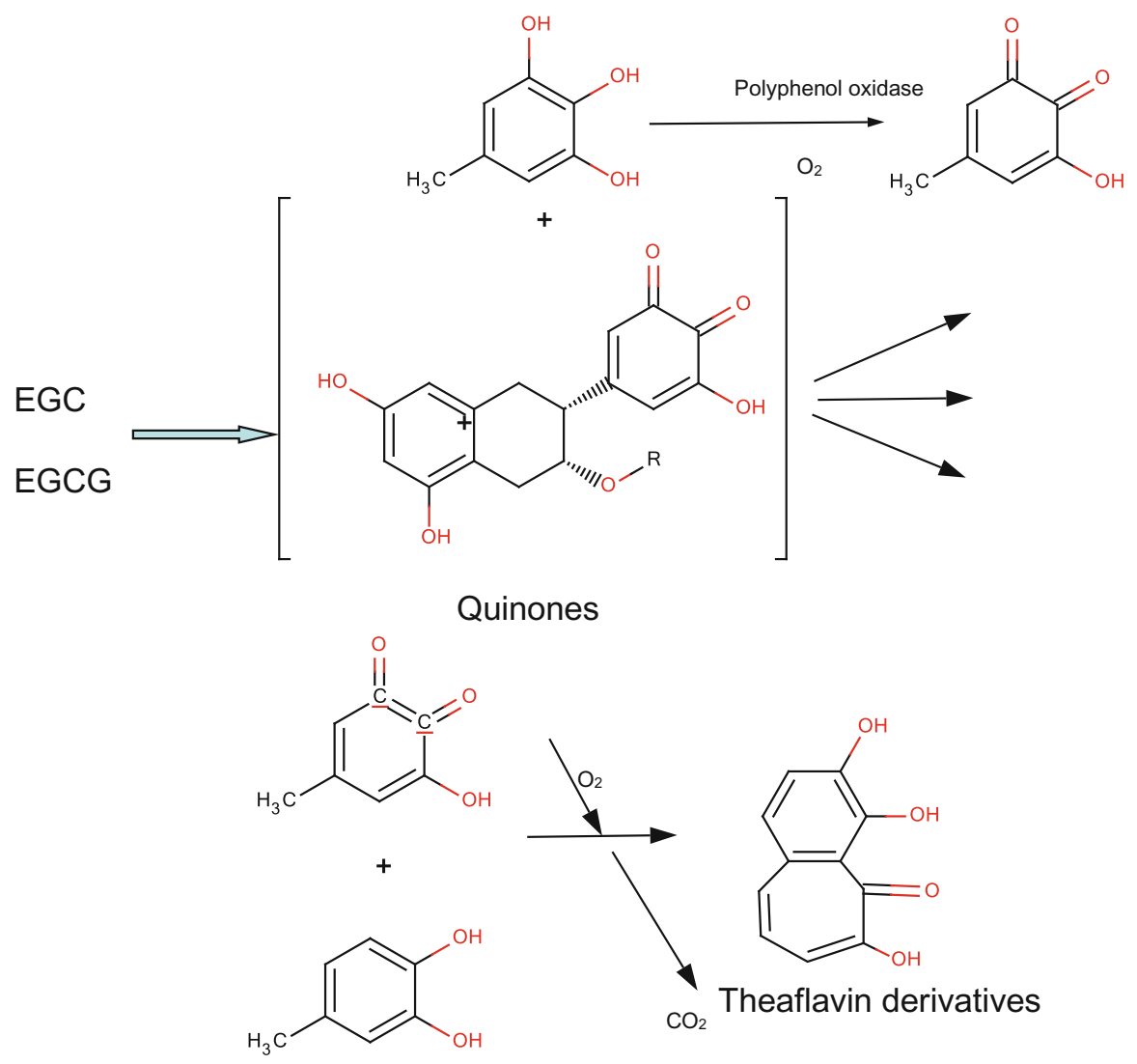

Epigallocatechin derivative quinones from EGC or EGCG

Fig. 5 The probable mechanism of synthesis of theaflavins during the fermentation process (Haslam 2003)

the synthesis of complicated polymeric polyphenols of black tea has still not been fully explained (Mahanta et al. 1993) (Fig. 5).

\subsection{Organoleptic Properties}

Theaflavins are orange or orange-red pigments, which determine the specific color and taste of black tea infusion. TFs were called a "golden molecules," because of their wide biological properties. Very often they are associated with the grade and quality of black tea, the most consumed tea in the world. Although both theaflavins and thearubigins are responsible for the specific taste and aroma of black tea, the first one are considered as the major group of compounds used to assess the market value, 
clonal variations, and seasonal quality variations of black tea (Yao et al. 2006). Theaflavins have astringent properties and give specific mouth-coating and longlasting oral sensation at the back of the throat. However their astringent properties are much lower, compared to catechins, and account for about $0.1 \%$ of the total astringency of all tea constituents (He 2017).

\subsection{Absorption and Metabolism of Theaflavins}

Bioavailability of theaflavins is very poor. Based on the plasma and urine concentrations, Mulder and co-workers established the intake rate at $0.0006 \%$, and PereiraCaro and co-investigators obtained even lower value of $0.000001 \%$ after oral ingestion of a mixture of theaflavins, which was an equivalent of $\sim 10$ cups of black tea (Mulder et al. 2001; Pereira-Caro et al. 2017). Ingested TFs pass through the gastrointestinal tract unchanged to the colon, where they are subjected to the action of the resident microbiota. As a result low molecular weight degradation products are formed, mainly hydroxybenzene derivatives, particularly pyrogallol-1sulfate, pyrogallol-2-sulfate and 3-(4'-hydroxyphenyl)propionic acid. Probably theaflavins are catabolized in the two pathways - first by colon microbiota and second by mammalian cell enzymes during phase II metabolism. Because of a very low TFs bioavailability, the beneficial role associated with the consumption of black tea is linked to their circulating metabolized products, which are mainly of microbial origin (Pereira-Caro et al. 2017).

\subsection{Bioactivity of Theaflavins}

In recent years many beneficial effects of TFs were revealed including in vitro and in vivo studies. Below some of the most important biological activities were described (examples were limited to animals and human studies).

\subsubsection{Antioxidant Activity}

It is already well-known and was confirmed in numerous studies that tea infusions possess strong antioxidant activity. Black tea infusions are now considered as a major source of dietary polyphenols for a general population. For many years this product was thought to be a weaker dietary antioxidant agent, compared to green tea, which seemed obvious, because over $75 \%$ of simple catechins are decomposed during fermentation process. However, recent findings revealed that the new compounds (e.g., theaflavins), which arise, are also characterized by strong radical scavenging activity. The ability to quench DDPH (2, 2-diphenyl-1-picrylhydrazyl) radical by theaflavins can be expressed as follows: $\mathrm{TF}_{3}>\mathrm{TF}_{2} \mathrm{~B}=\mathrm{TF}_{2} \mathrm{~A}>\mathrm{EGCG}>\mathrm{TF}_{1}$ (He 2017). This comparison shows that three major theaflavins are stronger antioxidants than EGCG, which is considered one of the most active antiradical molecules present in food. The randomized, double-blind, crossover study performed by Arent and co-workers on humans subjected to acute anaerobic interval training revealed 
beneficial effects of TFs intake. The study showed that the consumption of black tea enriched in theaflavins led to better recovery and reduced the oxidative stress. Moreover it reduced muscle pain caused by long anaerobic periods (Arent et al. 2010).

\subsubsection{Antimutagenic Activity}

The study performed on bone marrow cells of mice showed significant decrease in chromosomal aberrations and sister chromatin exchange caused by benzo[a]pyrene, after oral administration of black tea extract, which was equal to the consumption of five cups per day. This activity was mostly due strong antioxidant activity, which inactivated direct carcinogenesis (desmutagenicity) outside the cell. Other proposed mechanism linked this activity with the induction of P450 cytochrome enzymes, which results in the activation of intracellular detoxification of carcinogens. Moreover induction of DNA repair, inactivation of reactive forms of mutagens and carcinogenesis, as well as inhibition of promutagen activation, promotion, invasion, and metastasis of tumor cells are also mechanisms which underline the antimutagenic activity of theaflavins (Halder et al. 2005).

Wang and co-workers proved protective effects of theaflavins on cadmiuminduced $(0.4 \mathrm{mg} / \mathrm{kg}$ body weight, s.c., once a day) testicular toxicity in male Sprague-Dawley rats. The animals received 50, 100, and $200 \mathrm{mg} / \mathrm{kg}$ of TFs per body weight, orally, once a day during 5 weeks. The study revealed dose-dependent reduction of cell damage in testis and DNA damage, increased serum testosterone levels, and improved sperm characteristics. The authors also observed other beneficial effects of theaflavins administration, e.g., decrease in the production of MDA caused by $\mathrm{Cd}$; reduced concentration of this metal in the liver, testis, and blood; and increased excretion of cadmium with feces and urine (Wang et al. 2012).

\subsubsection{Influence on Blood Lipids}

Theaflavins were proved to inhibit the lipase and amylase and suppress the expressions of lipopolysaccharide-induced intercellular adhesion molecule and vascular cell adhesion molecule by blocking the activation of NF-KB and JNK in the epithelial cells of the intestine. Additionally TFs suppress lipogenesis by inhibiting fatty acid synthase, through downregulation of epidermal growth factor and receptor/PI3K/Akt/Sp-1 signal transduction pathway. As a result of all of these mechanisms, significant hypolipidemic effect was observed.

TFs were also shown to have strong effects toward the prevention of obesity by inhibition of hepatic lipid storage, reduction of lipid accumulation, and production of fatty acids and stimulation of their oxidation. After oral administration of TFs, increased energy expenditure and expression of metabolic genes were proved. Theaflavins are also considered to improve liver steatosis, oxidative stress, and inflammation and as a result decrease hepatocyte apoptosis (He 2017).

\subsubsection{Anti-inflammatory Activity}

Gosslau and co-workers proved $\mathrm{TF}_{2} \mathrm{~B}$ to have strong anti-inflammatory effect by the suppression of the 12-O-tetradecanoylphorbol-13-acetate-induced COX-2 gene 
expression and downregulation of TNF- $\alpha$, inducible nitric oxide synthase (iNOS), ICAM-1, and nuclear factor $\kappa \mathrm{B}(\mathrm{NF}-\mathrm{\kappa B})$. They have also reported that $\mathrm{TF}_{2} \mathrm{~B}$ significantly reduced ear edema in mouse, by producing similar pattern of gene downregulation to that observed in the cell model (Gosslau et al. 2011). $\mathrm{TF}_{3}$ was shown to have protective effect in colitis. Theaflavin derivatives were also proved to decrease the expression of the inflammatory cytokine IL-6, one of the most important mediators of inflammation (He 2017).

\subsubsection{Antimicrobial Activity}

Theaflavin-3, $3^{\prime}$-digallate $\left(\mathrm{TF}^{3}\right)$ during the epidemiological studies was shown to be strong inhibitor of 3C-like protease, related to severe acute respiratory syndrome (SARS). TFs were proved to have strong inhibitory effects against influenza and HIV viruses, by blocking the initial steps of infection through attenuation of neuraminidase and hemagglutinin activity (He 2017).

Other studies, performed using six clinical isolates of herpes simplex virus type 1 (HSV-1) and two clinical isolates of HSV-2, have shown that the combination of $\mathrm{TF}_{3}$ and lactic acid significantly reduced the infection caused by these viruses in the $\mathrm{pH}$ spectrum of 4.0-5.7, which mimic the conditions found in the female reproductive tract (Isaacs and Xu 2013).

Betts and co-workers revealed strong antibacterial effect of various concentrations of theaflavins toward eight clinical isolates of Stenotrophomonas maltophilia and Acinetobacter baumannii, important nosocomial pathogens, resistant to multiple antibiotics. They also proved significant synergism of action with epicatechin; however the mechanism of such activities was not elucidated (Betts et al. 2011).

\subsubsection{Anticancer Activity}

TFs were shown to have strong anticancer activity in numerous studies performed on human cancer cell lines, by blocking extracellular signal transmission and cell proliferation and improving cell shrinkage, membrane blebbing, and mitochondrial clustering. As a result of these mechanisms, the induction of cancer cells apoptosis was observed (He 2017).

Oral administration of theaflavin-enriched black tea extracts ( $40 \%$ of $\mathrm{TFs})$ to Sprague-Dawley rats with dimethylnitrosamine-induced liver fibrosis reduced necrosis, bile duct proliferation, inflammation, and elevated levels of serum GOT (glutamate oxaloacetate transaminase) and GPT (glutamic pyruvic transaminase). Studied extract was efficient at the dose of $50 \mathrm{mg} / \mathrm{kg}$ as well as $100 \mathrm{mg} / \mathrm{kg}$ per day. Hepatic fibrosis is a high-risk factor of developing hepatocellular carcinoma (HCC), which is the fifth most common cancer in men and the seventh in women globally (Weerawatanakorn et al. 2015a). Thus drinking black tea may have beneficial role in the prevention of HCC.

Tea polyphenols (including theaflavins) were observed to suppress the activation of aryl hydrocarbon receptor (AhR) induced by 2,3,7,8-tetrachlorodibenzo-p-dioxin (TCDD) ex vivo in rats. Conjuncted and intact forms of catechins and theaflavins were present in the plasma and liver of animals. These results confirmed that polyphenols from tea can be incorporated in the liver and through the AhR activation 
pathway may inhibit the activity of cytochrome P450 1A1 enzyme. Tea phenolics are also a promise chemopreventive agent in human prostate cancer. The relative bioavailability of theaflavins in the prostate tissue was $70 \%$ higher compared to EGCG. It was proved that tea polyphenols (catechins and theaflavins) are bioavailable in prostate, where they can act as anticancer agents (He 2017).

Lee et al. reported that theaflavin gallates are hydrolyzed by salivary esterases, which were proofed in either in vitro or in vivo studies, and high concentrations of theaflavins were observed in saliva in the first hour after oral administration of black tea brew. This might reflect that black tea infusions may play beneficial role in the prevention of oral cancer and dental carries (Lee et al. 2004).

\subsection{Safety: Toxicity and Side Effects}

Theaflavins should be considered as a safe and nontoxic natural product. In the literature there is no information on toxicity of TFs. The only information which might be found is that $\mathrm{TF}_{2} \mathrm{~A}$ and $\mathrm{TF}_{2} \mathrm{~B}$ could act as a prooxidants and increase oxidative stress. However it was observed in relation to cancer cells, which must be considered a beneficial activity (Babich et al. 2008).

\subsection{Marketed Product}

Theaflavins are present on the market as dietary supplements containing black tea extracts. Theaflavin Standardized Extract ${ }^{\circledR}$ produced by LifeExtension ${ }^{\circledR}$ contains $350 \mathrm{mg}$ of black tea extract, which is standardized to $25 \%$ of theaflavins per one capsule. The product is protected by US patent Nos. 6,811,799 and 6,602,527 and can be bought on the US market. The producer does not inform what are the proportions of particular theaflavins in the extract.

Theaflavin ${ }^{\circledR}$ produced by Seeds ${ }^{\circledR}$ is also a dietary supplement which contains black tea extract, together with green tea extract and vitamin E. However, the producer does not provide any information on the composition of this extract, except that it was produced from premium black tea. This product is also offered in the US market.

\subsection{Perspectives}

Taking into account lack of toxicity and side effects, numerous beneficial effects to the organism, which was presented above, and high daily intake with very popular black tea infusions, theaflavins can be potentially used in functional foods and nutraceuticals in the prevention of several lifestyle diseases, e.g., obesity, cancers, or diabetes. Other potential applications include liver diseases, dental carries, and reduction of toxicity caused by heavy metals (e.g., cadmium). Theaflavins are consumed every day by a large population of the world with black tea, so probably 
they are still acting, although we do not note or measure the effects of their action. Except that, TFs can be used as isolated compounds or purified extracts from tea as dietary supplements.

\section{$3 \quad$ Thearubigins}

\subsection{Biosynthesis and Structure}

Thearubigins (TRs) are the next polymeric polyphenols present in black tea, which (together with theaflavins) are responsible for specific brown color and aroma of the infusions. In the past TRs were considered as the insoluble fraction of ethyl acetate extraction of the black tea (Yao et al. 2006). Their content in black tea is about $12-18 \%$, and therefore they comprise the biggest part of all active constituents. TRs are synthetized during the same process as TFs, in which polyphenol oxidase and peroxidase are involved.

Thearubigins are compounds with a red-brown or dark brown color. Although the majority of catechins during fermentation are likely to be transformed into thearubigins, the structure and formation of these substances are still poorly understood. They are believed to be heterogeneous flavan-3-ols and their gallate derivates (Fig. 6). Some authors also suggest that theaflavins are involved in the formation of thearubigins (Haslam 2003). It seems that the pathway of TRs synthesis mainly involves EGC and EGCG and in the next steps quinone and then theaflavins and other benztropolones. Another route suggests participation of theasinensins.

The process of thearubigins synthesis resembles "the browning" - very often observed in nature, during which the plant tissues are damaged and oxidized, based on the quinone tanning, the Maillard reaction, or caramelization. TRs are a group of very closely structurally related polymeric compounds, which range from dimeric and trimeric to tetrameric and even greater structures and average molecular weight of 700-2000 (Haslam 2003).

\subsection{Organoleptic Properties}

Some of the authors suggest that most of the catechins present in fresh tea leaves are transformed into thearubigins during the fermentation process and therefore they constitute the final group of compounds during the production of black tea. TRs are water-soluble, acidic compounds, primarily responsible for rust brown color of the infusion. They are characterized by ill-defined chromatographic behavior, and since many years, little progress has been made toward an understanding of their chemical nature. It is proposed that thearubigins are mainly responsible for the red-brown color of the tea infusion; however its specific taste and aroma are mostly due to the presence of theaflavins (Khan and Mukhtar 2007). Due to their very high water solubility, thearubigins account up to $30-60 \%$ of the solids in black tea infusion. TRs 
Fig. 6 The proposed structure of thearubigins (Khan and Mukhtar 2007)

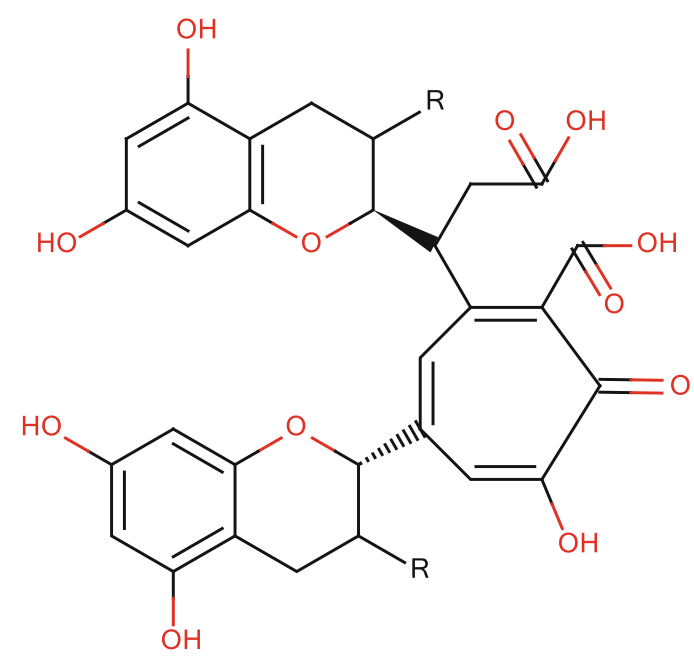

are very often associated with the richness of taste and therefore called a "body" of black tea (Yao et al. 2006).

\subsection{Biological Activity}

There are very few data on biological properties of thearubigins. Since their structure was not fully elucidated, there are no standards on which studies toward their activity may be conducted. Because there are very few information on that subject, below some studies on biological activities of TRs were presented, which can be found in the scientific literature.

Halder and co-workers proved significant antimutagenic effect of thearubigins. Fraction of TRs was extracted from black tea infusion by n-butanol liquid-liquid partition. Particular compounds were not separated and identified, but the total fraction was described as "thearubigins." For chromosome aberration assay (CA), the animals were fed by gavage and obtained three different concentrations of TRs (40, 80, and $160 \mathrm{mg} / \mathrm{kg}$ body weight). Immediately after the gavage, the animals were administrated benzo[a]pyrene (B[a]P) $(100 \mathrm{mg} / \mathrm{kg}$ body weight). For the analysis of $\mathrm{CA}$, the animals received colchicine, and $2 \mathrm{~h}$ later they were killed, and their bone marrow was expelled and subjected to the analysis. The study revealed significant reduction in $\mathrm{CA}$ in all the three different concentrations of thearubigins with $\mathrm{B}[\mathrm{a}] \mathrm{P}$ compared to the control group. The treatment with TRs significantly reduced both the chromatid and chromosome types of aberrations (Halder et al. 2005).

The same authors performed in vivo sister chromatid exchange (SCE) test in mice using TR fraction. All the steps of the treatment were the same as in CA analysis. Obtained results showed significant anticlastogenic effect of orally administrated 
thearubigins as measured by SCE against $\mathrm{B}[\mathrm{a}] \mathrm{P}-\mathrm{a}$ strong mutagen. All three tested concentrations of TRs showed significant reduction toward the frequency of SCE (Halder et al. 2005).

TRs showed significant antimutagenic properties against $\mathrm{B}[\mathrm{a}] \mathrm{P}$ in the in vitro plate test using four different Salmonella strains (TA97a, TA98, TA100, and TA102). Obtained results showed significant antimutagenic activity of thearubigins.

The authors concluded that in the CA assay, TRs showed two times lower protective effects compared to TFs fraction, and in the SCE study, TFs revealed about three times more protective effects compared to TRs. Interestingly thearubigins showed different activity in two different test systems. Their activity was much higher in in vivo mammalian cells than in in vivo bacterial systems. Antimutagenic and anticlastogenic activity of thearubigins is the same as in the case of theaflavins, probably due to their antioxidant properties, which inactivate the extracellular activity of direct carcinogens. Thearubigins also increase the activity of cytochrome P450, which results in the enhancement of the intracellular detoxification of carcinogens.

Catterall and co-workers investigated antimutagenic effects of theafulvins (a fraction of thearubigins) in vivo using male Wistar albino rats, against several dietary carcinogens (heterocyclic amines, polycyclic aromatic hydrocarbons, and nitrosamines). The study showed concentration-dependent significant reduction of the mutagenicity of 2-amino-3-methyumidazo-[4,5-f]quinoline, 2-amino-1-methyl-6phenylimidazo[4,5-fc]pyridine, benzo[a]pyrene, 7,12-dimethylbenz[a]anthracene, nitrosopyrrolidine, and nitrosopiperidine. However the mutagenicity of aflatoxin B1 was increased (Catteral et al. 1998).

The antioxidant activity of black tea is well-known and is due to the simple phenolics like catechins, as well as theaflavins and thearubigins. All of these groups of compounds, because of their phenolic nature, have strong antioxidant properties. However the knowledge and studies on this subject for particular polyphenols of black tea may be classified as follows: catechins $>\mathrm{TFs}>>$ TRs. The antioxidant activity of thearubigins is definitely the least well-known.

Study on the antioxidant activity of TRs rich fraction, performed using different in vitro and in vivo systems (e.g., DPPH, ABTS, FRAP, or hydrogen peroxide assays and protection of different biomolecules against oxidative stress in rats), revealed similar activity of both thearubigin- and theaflavin-rich fractions. Once again it was proofed that strong antioxidant potential of black tea is the resultant of activity of all compounds of phenolic nature present in black tea leaves. Thus in some situations, black tea is described as a more potent antioxidant agent compared to green tea (e.g., stronger lipid peroxidation inhibitor) (Sinha and Ghaskadbi 2013).

Imran and co-workers studied the influence of theaflavins and thearubigins on antioxidant status and lipid peroxidation in rats. They have proved that TFs exhibited higher antioxidant activity. Animals receiving a diet rich in both TFs and TRs were characterized by significant reduction in lipid profile, glucose content, and renal function. Moreover this study revealed that animals receiving TFs were characterized by lower values in the TBARS test (thiobarbituric acid reactive substances), which is one of the most widely used assays for measuring lipid peroxidation end 
product - malondialdehyde and lipid profile, compared to thearubigins or a mixture of TFs and TRs (1:1). On the other hand, theaflavins+thearubigins diets caused the highest glucose, urea, and creatinine decrease and maximum level of insulin and antioxidant parameters compared to diets containing theaflavins or thearubigins alone (Imran et al. 2018).

The antioxidant activity of particular constituents of black tea can be characterized as follows: $\mathrm{TF}_{3}>\mathrm{EGC}>$ the mixture of $\mathrm{TF}_{2} \mathrm{~A}$ and $\mathrm{TF}_{2} \mathrm{~B}>$ thearubigins $>\mathrm{TF}_{1}$. It should be also noted that studies regarding the antioxidant activity of particular black tea polyphenols are inconclusive, mainly because of different systems and parameters used. However many data suggest that the strongest active compound is TF3, followed by simple catechins. Thearubigins, although considered as strong antioxidant agents, are classified much less active compared to catechins or theaflavins.

\subsection{Conclusion}

Because of the limited data and only few scientific studies regarding thearubigins, it is not easy to predict a future perspective for this group of compounds. There are no information on toxicity of these compounds, but taking into consideration that they are a basic constituent of black tea, thus a significant ingredient of human daily data, their toxicity and side effects should be considered low.

Except dietary supplements containing total extracts from the black tea or isolated theaflavins, there are no products on the market with isolated thearubigins or fractions rich in these compounds. However majority of people consume TRs every day while drinking black tea infusions. Taking into account how popular is this beverage, thearubigins should be considered significant constituent of human diet, being simultaneously one of the most important non-nutrients.

\section{Theasinensins}

Black tea is definitely the most popular type of tea, which accounts for almost $78 \%$ of the global production. It is mainly consumed in the United States and Europe. Green tea is mostly preferred in Asian countries, and its market share is estimated to be ca. $20 \%$. The third most popular type is oolong tea, consumed mainly in Taiwan, southern China, and many Eastern countries. Although its production is only $2 \%$ of the global market and thus it is far below the most popular types, namely, black and green, its popularity is still increasing. During the last two decades, its production in China has almost doubled, from $67.6 \times 10^{3}$ metric tons in 2000 to $254 \times 10^{3}$ metric tons in 2014 (Weerawatanakorn et al. 2015b).

Oolong is a semi-fermented type of tea, and the degree of catechin oxidation is in a wide range of $10-80 \%$, depending on the consumer requirements. Apart from the degree of fermentation, all three types of tea are also differentiated based on its amino acid content, mainly L-theanine but also alanine, leucine, serine, or glutamic 
Table 3 The composition of oolong tea beverage (Sajilata et al. 2008)

\begin{tabular}{l|l}
\hline Compound & Content $(\mathrm{mg} / 100 \mathrm{~mL})$ \\
\hline Catechin & 1.65 \\
\hline Gallocatechin & 6.65 \\
\hline Epigallocatechin & 16.14 \\
\hline Epicatechin & 5.08 \\
\hline Catechin gallate & 0.6 \\
\hline Epicatechin gallate & 5.73 \\
\hline Epigallocatechin gallate & 25.73 \\
\hline Gallocatechin gallate & 1.85 \\
\hline Gallic acid & 2.19 \\
\hline Caffeine & 23.51 \\
\hline Polymerized polyphenols & 33.65 \\
\hline Total polyphenols & 99.32 \\
\hline
\end{tabular}

acid. Oolong tea has specific taste and aroma, depending on several parameters like smell of volatile fragrance, umami (specific taste, hard to explain), and degree of astringency versus sweetness (Alcazar et al. 2007).

Major components of oolong tea can be divided into two groups: simple catechins and polymeric polyphenols. Since this type of tea is a semi-fermented product, the degree of catechin degradation changes, and thus the concentration of polymeric compounds differs. Sajilata and co-workers characterized the composition of oolong tea beverage as follows (Table 3).

Major secondary polyphenols in black tea are theaflavins and thearubigins, which were previously described. However oolong tea contains another class of polymeric polyphenols, known as theasinensins.

\subsection{Biosynthesis and Structure}

In 1958 Robert discovered a new group of compounds, known as bisflavanols A, B, and C, which were formed by linkage of two EGCG molecules. Later, in 1984, this group of polymeric oxidized flavan-3-ols was isolated from oolong tea and identified as theasinensins A, B, and C. In 1988 Nonaka and Hashimoto confirmed the presence of other compounds of this type, which were named using the letters D, E, F, and G (Weerawatanakorn et al. 2015b).

Theasinensins are considered as bioactive flavonoids of oolong tea. They are formed by the coupling of two catechins at their B rings through a C-C molecular bond. Its structure was presented in Fig. 7.

The structures of theasinensins A, B, and C contain the biphenyl bonds in the configuration R, whereas in D and E, it is R-biphenyl configuration (Fig. 7). Some authors suggest that theasinensins $\mathrm{D}$ and $\mathrm{E}$ are just stereoisomers of $\mathrm{A}$ and $\mathrm{C}$. If we consider basic monomers which build particular TSs, it visible that theasinensins $\mathrm{A}$ and D are dimers of EGCG with an R- and an S-biphenyl bond and theasinensin B is 

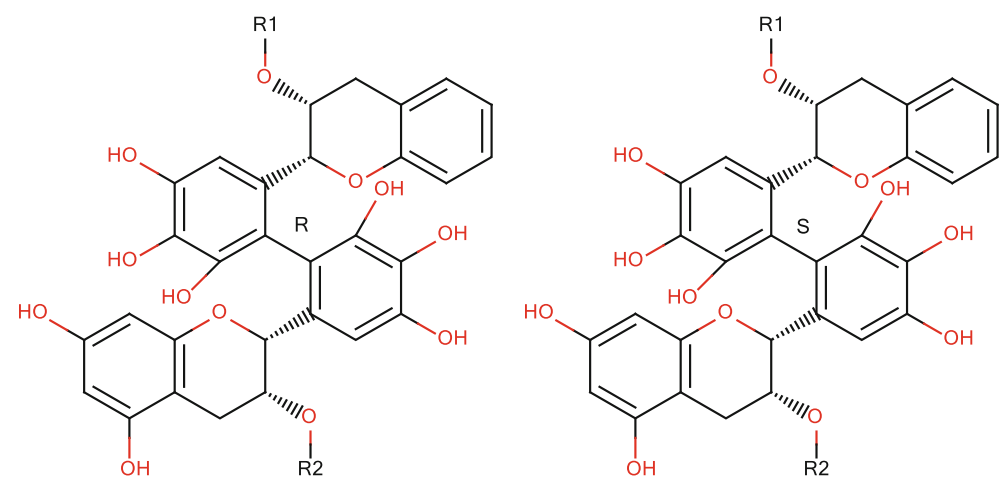

\begin{tabular}{|c|c|c|c|}
\hline \multicolumn{2}{|c|}{ R stereoisomers } & \multicolumn{2}{c|}{ S stereoisomers } \\
\hline Theasinensin A & $\mathrm{R} 1=\mathrm{R} 2=$ Galloyl & Theasinensin D & $\mathrm{R} 1=\mathrm{R} 2=$ Galloyl \\
\hline Theasinensin B & $\mathrm{R} 1=$ Galloyl & & \\
Theasinensin C & $\mathrm{R} 2=\mathrm{H}$ & Theasinensin E & $\mathrm{R} 1=\mathrm{R} 2=\mathrm{H}$ \\
\hline
\end{tabular}

Fig. 7 The structures of theasinensins (Weerawatanakorn et al. 2015b)

the dimer formed by the conjunction of EGCG and EGC, whereas theasinensin $\mathrm{C}$ is a dimer of EGC (Tanaka et al. 2003; Matsuo et al. 2006).

Theasinensins can be found in fermented teas, namely, black and oolong. They are synthetized during the fermentation process, in which the two dominant catechins in fresh tea leaves - EGCG and EGC - are oxidized by polyphenol oxidase. As a result corresponding quinone derivative is produced, which undergoes stereoselective dimerization to produce theasinensin (Tanaka et al. 2003).

The pathways in which TSs are formed are very interesting. Hashimoto concluded that theasinensins are much more easily synthetized by polyphenol oxidase, compared to theaflavins (Hashimoto et al. 1992). The crucial point during the formation of TSs is the enzymatic oxidative coupling of pyrogallol rings of EGCG. This reaction could be also conducted using chemical agents. There are different pathways in which theasinensins and theaflavins are formed. The latter one are formed during the oxidative condensation reaction between catechol moiety of EC or ECG and a pyrogallol moiety of EGC and EGCG, which was described previously. The pathway in which theasinensins are formed involves conjunction of pyrogallol-type B rings of EGCG and EGC. TFs are synthetized in the first step of black tea production, when leaves are crushed and kneaded. At this point TSs are not observed. They are formed when the leaves are heated in the temperature of $80{ }^{\circ} \mathrm{C}$. One of the most important intermediates during the synthesis of TSs is unstable 
dehydrotheasinensins. They are formed from the oxidation of pyrogallol-type B ring catechins. During the final stage of black and oolong tea production (heating and drying process of the tea leaves), dehydrotheasinensins undergo redox dismutation to form corresponding theasinensins. It was elucidated that the transformation of dehydrotheasinensin A gives theasinensins A and D. Moreover it was implied that this process may be a nonenzymatic process, which spontaneously occurs during heating and drying of the tea leaves. Such a process may be also conducted in vitro in the nonenzymatic way (Weerawatanakorn et al. 2015b). Shii and co-workers obtained dehydrotheasinensin A by a nonenzymatic oxidation of EGCG by copper salts at the room temperature and $\mathrm{pH} 4-5$. The efficacy of the reaction increased with the elevated temperature (Shii et al. 2011).

\subsection{Biological Properties of Theasinensins}

Although the scientific literature is rich in information on the biological properties of green and black teas, the data regarding oolong tea and its main active compounds theasinensins - are still limited. Because majority of experiments evaluating biological activity of theasinensins are in vitro experiments, and oolong tea is the tea most equated with theasinensins, below in vivo studies on the activity of the pure compounds as well as its main source were presented.

\subsubsection{Antioxidant Activity}

It is obvious that, taking into account, that the main active ingredients of oolong tea are polyphenols, this product will be strong antioxidant agent - similar to green and black teas. In vivo study revealed that the consumption of oolong tea temporarily moderately increased the antioxidant capacity of human plasma. It was further observed that oolong tea reduced oxidative stress and DNA damage caused by free radicals (Higdon and Frei 2003). Study performed on athletes revealed that the consumption of oolong tea for 30 days significantly reduced the levels of malondialdehyde at rest and after exercise. The resting levels of SOD (superoxide dismutase) were also reduced. Moreover it was found that oolong tea decreased the level of lipid peroxidation and normalized the cholesterol profiles (Tsai et al. 2005). Theasinensin $\mathrm{C}$, among all theasinensins isomers, was considered as the strongest antioxidant agent against lipid peroxidation (Weerawatanakorn et al. 2015b).

\subsubsection{Anti-inflammation}

Several studies demonstrated anti-inflammatory activity of oolong tea and its active constituents. It was shown that ethanol extract from oolong tea increased angiogenesis and adiponectin gene expression in epididymal fat, which was considered as anti-inflammatory effect. Moreover this extract was proofed to have beneficial effects on metabolism and inflammation through pro-angiogenic activity during adipose tissue expansion (Weerawatanakorn et al. 2015b). On the molecular basis, it was shown that ethanol extract from oolong tea reduced the concentration of monocyte chemoattractant protein-1 (MCP-1) in serum, a small cytokine responsible 
for gathering monocytes, memory $\mathrm{T}$ cells, and dendritic cells to the site of injury (Tchernof and Despres 2013). Moreover it was elucidated that theasinensins A and D reduced LSP-induced COX-2 and $\mathrm{PGE}_{2}$ synthesis, and this effect was stronger in the case of theasinensins B, C, and E. It was proposed that the galloyl moiety (present in the isomers $\mathrm{A}$ and $\mathrm{D}$ ) plays an important role in anti-inflammatory activity of this group of compounds (Hou et al. 2010). It was also discovered that theasinensin A caused changes in 1382 genes responsible for chemokines, interleukins, and interferons production, thus strongly interfering in the immune defense system (Chen et al. 2011). Continuation of experiments elucidated new molecular pathways of the influence of theasinensins on immune defense components - theasinensin A significantly reduced the levels of inflammatory mediators like inducible oxidase synthetize (iNOS), nitric oxide (NO), interleukin-12 (p70) (IL-12), tumor necrosis factor alpha (TNF- $\alpha$ ), and MCP-1. Cell signaling pathways were also modified through the action of theasinensin A - downregulation of MAPK/ERK kinase (MEK)-extracellular signal-regulated kinase (ERK) signaling through a direct binding to MEK-ERK was proofed (Weerawatanakorn et al. 2015b). These findings were confirmed in the mouse paw edema model - theasinensin A inhibited the production of IL-12 (p70), TNF- $\alpha$, and MCP- 1 and attenuated the inflammation in mouse paw edema caused by lipopolysaccharide LPS (Hisanaga et al. 2014).

\subsubsection{Anti-obesity Activity}

Oolong tea was proofed to possess significant activity toward the reduction of weight. Although such experiments were not conducted for particular theasinensins, a study performed on high-fat diet-induced obese mice revealed reduction of fat production through the inhibition of pancreatic amylase. This caused significant decrease in lipid absorption and increased lipid excretion into the feces. Another study demonstrated that the supplementation with oolong tea reduced the concentration of LDL-cholesterol, total cholesterol, and triacylglycerols in serum plasma in rats and decreased their weight. Oolong tea was also proofed to strongly decrease the levels of triacylglycerols in comparison to green tea. Oolong tea was also proofed to increase plasma levels of SOD and weight ratios of the liver to epididymal adipose tissue in rats. The fact that oolong tea reduces the levels of MCP-1, a protein which concentration is positively associated with higher incidence of obesity, indicates that active constituents of oolong tea may play a beneficial role in the prevention of this disease (Weerawatanakorn et al. 2015b).

\subsubsection{Anticancer Activity}

Several studies reported that oolong tea may be characterized by strong cancerchemopreventive properties, similar to green or black teas. Some authors suggested that catechins play a dominant role and were mostly responsible for this activity. However there are not much research performed to investigate anticancer activity of theasinensins. In theory since initiation and/or prolongation of different types of cancers is connected with inflammation and generation of free radicals, significant anti-inflammatory and antioxidant properties of theasinensins may play a crucial role in cancer prevention caused by oolong tea and its active constituents. In vitro studies 
revealed molecular basis of potential anticancer activity of TSs. Using two cell lines - human histolytic lymphoma (U937) and acute T-cell leukemia (Jurkat) - it was shown that theasinensin A, extracted from oolong tea, induced apoptosis through the release of cytochrome $\mathrm{c}$ into the cytosol and activation of caspase-9 and caspase-3, loss of mitochondrial transmembrane potential, and elevation of free radicals production (Pan et al. 2000). Maeda-Yamamomota and co-workers investigated potential role of tea polyphenols in the inhibition of metastasis using human fibrosarcoma HT1080 cells. The study revealed weak antimetastatic activity of theasinensin D in comparison to theaflavin and ECG, which was considered as the most active (Maeda-Yamamoto et al. 1999).

There are limited data on anticancer activity of particular theasinensins in the in vivo model. Study performed by Zhang and co-workers revealed that oolong tea, similar to black and green teas, induced apoptosis and arrested cell cycle in male Donryu rats (Zhang et al. 2000). However no particular theasinensins were used in this experiment, so it is not obvious if this activity was caused by catechins, TSs, or other active compounds present in oolong tea extract. Oral administration of theasinensin $\mathrm{A}$ in mice with carbon tetrachloride (CCl4)-induced fibrosis relieved liver injury and ameliorated liver functions. Immunohistological staining has shown that supplementation with theasinensin A reduced collagen deposition and inhibited inhibition of transforming growth factor $\beta$ (TGF- $\beta$ ). It was concluded that theasinensin A may be considered as a potential bioactive compound from oolong tea, which prevents liver fibrosis (Hung et al. 2017). Based on previous studies, it could be concluded that chemopreventive effects of oolong tea extracts are due to its anti-inflammatory, antimutagenic, and anti-genotoxic activity; however there are still not many experiments performed on pure theasinensins in the in vivo model (Weerawatanakorn et al. 2015b).

\subsubsection{Hypoglycemic Effect}

Aqueous extract from oolong tea, similar to green and black teas, was proofed to increase insulin activity by 15 -fold in an epididymal fat cell assay (Anderson and Polansky 2002). No impact of oolong tea on $\mathrm{Na}^{+}$-dependent glucose cotransporter (SGLT1) was shown in frogs (Xenopus oocytes) compared to tea catechins (Hossain et al. 2002). A study performed on 20 people (women and men, average age of 61.2 years) suffered from diabetes since almost 5 years, which have obtained $1500 \mathrm{~mL}$ of oolong tea per day for 30 days, revealed significant decrease of plasma glucose from 229 to $162.2 \mathrm{mg} / \mathrm{dL}$ and fructosamine from 409.9 to $323.3 \mu \mathrm{mol} / \mathrm{L}$. Water was used as control. It was also proofed that the combination of oolong tea and hypoglycemic drugs can cause stronger effects toward reducing blood glucose than taking the drugs alone (Hosoda et al. 2003). It was indicated that crucial compounds of oolong tea responsible for this activity are theasinensins. Studies performed in mice and rat models revealed that theasinensin A reduces serum glucose levels by over $30 \%$, inhibits glucose production and absorption in the intestine through suppression of $\alpha$-glucosidase activity, and induces antihyperglycemic responses by suppressing fat absorption. Other studies performed using cell lines have shown that theasinensins $\mathrm{A}$ and $\mathrm{B}$ can promote glucose cell uptake and improve insulin 
resistance by regulation of GLUT 4, which is insulin-regulated glucose transporter present predominantly in adipocyte and striated muscle tissue. It was also revealed that this mechanism differs from EGCG, which can also regulate the activity of GLUT 4 (Weerawatanakorn et al. 2015b).

\subsubsection{Prevention of Cardiovascular Diseases}

There are epidemiological studies which have proofed beneficial effects of oolong tea consumption toward the cardiovascular system. An epidemiological study was performed on 1507 subjects from Taiwan. The study revealed that 600 were habitual tea drinkers (green or oolong tea) who consumed at least $120 \mathrm{~mL}$ of tea infusion per day during the period of 1 year or more. The study revealed that in the group of habitual tea drinkers, the risk of developing hypertension was reduced by $46 \%$ for those who drank 120-599 mL of tea per day and was further reduced by $65 \%$ for those who drank $600 \mathrm{~mL}$ or more. Unfortunately the study did not separate people who drink green from oolong tea (Yang et al. 2004). Since high-fat and cholesterol diet was proved to increase the risk of atherosclerosis and coronary heart disease, activities leading to decrease lipid intake and absorption and causing higher energy expenditure (EE) are considered crucial in decreasing the risk of cardiac diseases. Hsu and co-workers have shown that the consumption of polyphenol-enriched oolong tea increases fecal lipid excretion in patients taking high-fat diet (Hsu et al. 2006). Moreover, a study performed on 11 healthy Japanese women proved beneficial effects of oolong tea drinking for the increase of energy expenditure. This experiment showed that oolong tea increased EE by $10 \%$ and green tea by $4 \%$. Since green tea contains on average two times more caffeine and EGCG in comparison to green tea, the authors suggested that polymerized polyphenols present in oolong tea, of which theasinensins are the major fraction, are responsible for this activity (Komatsu et al. 2003). Study performed by Rumpler and co-workers revealed similar results, oolong tea consumption increased EE and fat oxidation. Its consumption can help to maintain low body weight and reduce the risk of atherosclerosis and hypertension (Rumpler et al. 2001). Oolong tea was proved to reduce the atherogenic index and increased the HDL-total cholesterol ratio in rats fed with high-fat diet (Yang and Koo 1997). Above findings confirmed beneficial effects of oolong tea consumption on the prevention of cardiovascular diseases; however there is still lack of data on the bioactivity of theasinensins toward heart diseases which could be found in the literature.

\subsubsection{Antimicrobial Activity}

Several studies have reported the activity of oolong tea extracts or particular theasinensins toward the inhibition of pathogen growth. Among them the following strains may be mentioned: Streptococcus sobrinus 6715, Bacillus subtilis, Escherichia coli, Proteus vulgaris, Pseudomonas fluorescens, Salmonella sp., S. mutans MT8148R, and Staphylococcus aureus (Weerawatanakorn et al. 2015b). All of these studies were performed in vitro, and no in vivo studies for antimicrobial activity of theasinensins can be found in the scientific literature at the moment. 


\subsection{Conclusions}

Theasinensins are still poorly understood. There is a need to continuing studies on the content of particular TSs in black and oolong teas. As for now there are some reports which showed that the major theasinensin is theasinensin A, which concentration was higher compared to theasinensins B and D. It was also proved that the concentration TSs in oolong tea is $0.65 \%$ and was much higher compared to green tea $(0.05 \%)$. More studies regarding the activity of particular theasinensins in the in vivo model, as well as scientific data regarding their absorption, metabolism, and microbial degradation, are needed to extend the knowledge on these polymerized polyphenols.

\section{Patents}

The screening for patents regarding polymeric polyphenols from tea gives over 7,000 of results. The biggest part regards theaflavins (almost 5,000 results), which are the best-studied from all condensed tea polyphenols. The majority of these inventions disclose the production process, biological activity, and usage as food components or dietary supplements. The table below shows selected patents regarding theaflavins, thearubigins, and theasinensins (Table 4).

\section{Summary}

Tea contains a large number of active substances. Its positive influence on the human organism is known since centuries. During production process of fermented and semi-fermented teas (mainly black and oolong), simple catechins are oxidized to form polymeric polyphenols. These substances have not been fully understood yet, and studies on understanding their structure, synthesis pathways, and biological properties are still carried out. Currently, it is known that they have many beneficial effects on the body and in the future they can be used in the pharmaceutical and food industry on a much larger scale than at present. 
Table 4 Selected patents regarding polymeric polyphenols from tea

\begin{tabular}{|c|c|c|c|c|}
\hline Patent number & Country & Title & Brief description & Year \\
\hline \multicolumn{5}{|l|}{ Theaflavins } \\
\hline CN101096693A & China & $\begin{array}{l}\text { Method for preparing } \\
\text { theaflavin and } \\
\text { thearubigin from fresh } \\
\text { green tea }\end{array}$ & $\begin{array}{l}\text { The invention discloses } \\
\text { a making method of } \\
\text { theaflavin and Congo } \\
\text { red element from fresh } \\
\text { green tea, without using } \\
\text { toxic and harmful } \\
\text { organic solvents }\end{array}$ & 2007 \\
\hline US7157493B2 & USA & $\begin{array}{l}\text { Methods of making and } \\
\text { using theaflavin, } \\
\text { theaflavin-3-gallate, } \\
\text { theaflavin-3'-gallate } \\
\text { and theaflavin 3,3'- } \\
\text { digallate and mixtures } \\
\text { thereof }\end{array}$ & $\begin{array}{l}\text { The invention discloses } \\
\text { methods of making a } \\
\text { mixture of theaflavin, } \\
\text { theaflavin-3-gallate, } \\
\text { theaflavin- } 3^{\prime} \text {-gallate, } \\
\text { and theaflavin } 3,3^{\prime} \text { - } \\
\text { digallate, usage in } \\
\text { pharmaceutical industry } \\
\text { and production of } \\
\text { dietary supplements }\end{array}$ & 2003 \\
\hline CN1729807A & China & $\begin{array}{l}\text { Process for preparing } \\
\text { keemun black tea with } \\
\text { highly concentrated } \\
\text { theaflavin and } \\
\text { thearubigins }\end{array}$ & $\begin{array}{l}\text { The invention discloses } \\
\text { a process for preparing } \\
\text { keemun black tea rich in } \\
\text { theaflavins and } \\
\text { thearubigins }\end{array}$ & 2004 \\
\hline US5532012A & USA & $\begin{array}{l}\text { Process for preparation } \\
\text { of purified tea } \\
\text { components using } \\
\text { preconcentration by } \\
\text { cream separation and } \\
\text { solubilization followed } \\
\text { by medium pressure } \\
\text { chromatography and/or } \\
\text { preparative HPLC }\end{array}$ & $\begin{array}{l}\text { The invention describes } \\
\text { a method of obtaining } \\
\text { selected tea } \\
\text { polyphenols, including } \\
\text { theaflavins, using liquid/ } \\
\text { liquid extraction and } \\
\text { chromatographic } \\
\text { techniques }\end{array}$ & 1995 \\
\hline CN101808529A & China & $\begin{array}{l}\text { Process for extracting } \\
\text { theaflavins from tea }\end{array}$ & $\begin{array}{l}\text { The invention describes } \\
\text { process of extraction of } \\
\text { theaflavins from tea } \\
\text { leaves using water and } \\
\text { ethyl acetate } \\
\text { simultaneously or } \\
\text { sequentially. As the } \\
\text { result ethyl acetate } \\
\text { extract rich in } \\
\text { theaflavins is obtained }\end{array}$ & 2007 \\
\hline US20090098224A1 & USA & $\begin{array}{l}\text { Metabolic-enhancing } \\
\text { properties of theaflavins } \\
\text { and thearubigins }\end{array}$ & $\begin{array}{l}\text { The invention } \\
\text { discovered that } \\
\text { theaflavins and } \\
\text { thearubigins reduce } \\
\text { appetite and adipose } \\
\text { tissue, increase } \\
\text { metabolism and energy } \\
\text { expenditure, and } \\
\text { enhance lean body mass }\end{array}$ & 2007 \\
\hline
\end{tabular}


Table 4 (continued)

\begin{tabular}{l|l|l|l|l}
\hline Patent number & Country & Title & Brief description & Year \\
\hline CN102524536A & China & $\begin{array}{l}\text { Application of theaflavin } \\
\text { as feed additive and } \\
\text { corresponding feed }\end{array}$ & $\begin{array}{l}\text { Application of } \\
\text { theaflavin as the food } \\
\text { additive in the } \\
\text { concentration of } \\
0.015-0.045 \% \text { in } \\
\text { different foods, e.g., fish } \\
\text { meal, bean pulp, or } \\
\text { peanut meal }\end{array}$ & 2011 \\
\hline JP2009268420A & Japan & $\begin{array}{l}\text { Functional food } \\
\text { composition }\end{array}$ & $\begin{array}{l}\text { The purpose of the } \\
\text { invention is to produce a } \\
\text { functional food with an } \\
\text { inhibitory potential } \\
\text { toward } \alpha \text {-glucosidase } \\
\text { and lipase containing } \\
\text { different theaflavins in } \\
\text { the concentration of } \\
\text { 2-10\% }\end{array}$ & 2008 \\
& & &
\end{tabular}

\begin{tabular}{l|l|l|l|l}
\hline Thearubigins & China & $\begin{array}{l}\text { Method for extracting } \\
\text { and separating } \\
\text { thearubigins from black } \\
\text { tea }\end{array}$ & $\begin{array}{l}\text { The invention describes } \\
\text { method for separation of } \\
\text { thearubigins from black } \\
\text { tea using simple } \\
\text { extraction equipment. } \\
\text { The biggest advantages } \\
\text { of the proposed method } \\
\text { are low costs, high } \\
\text { efficiency, and low } \\
\text { impact on the } \\
\text { environment }\end{array}$ & 2009 \\
\hline CN101518597A & China & $\begin{array}{l}\text { Application of } \\
\text { thearubigins to } \\
\text { pharmacy }\end{array}$ & $\begin{array}{l}\text { The invention describes } \\
\text { a new purpose of } \\
\text { thearubigins in the field } \\
\text { of pharmacy as natural } \\
\text { products which can be } \\
\text { used for treating or } \\
\text { preventing type II } \\
\text { diabetes, lipogenous } \\
\text { diabetes, and adiposis. } \\
\text { Moreover the invention } \\
\text { proves that thearubigins } \\
\text { have no toxic side } \\
\text { effects and are safe and } \\
\text { reliable to take }\end{array}$ & \\
\hline CN108522674A & China & $\begin{array}{l}\text { The invention describes } \\
\text { the production process } \\
\text { of high-quality black } \\
\text { tea. One of the } \\
\text { advantages is the } \\
\text { promotion of theaflavin } \\
\text { and thearubigin }\end{array}$ & 2018 \\
Rrocessing method of \\
high-quality black tea
\end{tabular}


Table 4 (continued)

\begin{tabular}{|c|c|c|c|c|}
\hline Patent number & Country & Title & Brief description & Year \\
\hline & & & $\begin{array}{l}\text { formation through the } \\
\text { increased oxidation of } \\
\text { simple catechins by } \\
\text { polyphenol oxidase and } \\
\text { beta-D-glucosidase }\end{array}$ & \\
\hline CN106509478A & China & $\begin{array}{l}\text { Feed additive for } \\
\text { improving immunity and } \\
\text { antioxidation ability of } \\
\text { river crabs and } \\
\text { preparation method } \\
\text { thereof }\end{array}$ & $\begin{array}{l}\text { Composition of food } \\
\text { additive, containing } \\
\text { among others } 20-40 \\
\text { parts of thearubigin, for } \\
\text { improving the immunity } \\
\text { and antioxidation ability } \\
\text { of river crabs }\end{array}$ & 2016 \\
\hline CN107156310A & China & $\begin{array}{l}\text { Instant health-care } \\
\text { antiaging soybean milk } \\
\text { powder }\end{array}$ & $\begin{array}{l}\text { The invention relates to } \\
\text { the technical field of } \\
\text { production of instant } \\
\text { health-care antiaging } \\
\text { soybean milk powder } \\
\text { containing among others } \\
\text { thearubigin }\end{array}$ & 2017 \\
\hline CN105285189A & China & $\begin{array}{l}\text { Making method of black } \\
\text { tea cakes }\end{array}$ & $\begin{array}{l}\text { The invention describes } \\
\text { the production of black } \\
\text { tea cakes rich in } \\
\text { thearubigins with the } \\
\text { reduced amounts of } \\
\text { theaflavins }\end{array}$ & 2015 \\
\hline CA2762665A1 & Canada & $\begin{array}{l}\text { A prebiotic composition } \\
\text { comprising thearubigin }\end{array}$ & $\begin{array}{l}\text { The invention proposes } \\
\text { the usage of black tea } \\
\text { polyphenols (containing } \\
82 \% \text { of thearubigins) as } \\
\text { a prebiotic and/or for the } \\
\text { treatment or prevention } \\
\text { of conditions associated } \\
\text { with poor gut health or } \\
\text { low immunity }\end{array}$ & 2010 \\
\hline CN106578219A & China & $\begin{array}{l}\text { Method for highly } \\
\text { efficiently purifying } \\
\text { thearubigins prepared } \\
\text { through chemical } \\
\text { oxidation of tea } \\
\text { polyphenol }\end{array}$ & $\begin{array}{l}\text { The invention describes } \\
\text { purification methods of } \\
\text { thearubigins obtained } \\
\text { through chemical } \\
\text { oxidation of tea } \\
\text { polyphenols. The } \\
\text { method removes sodium } \\
\text { chloride with high } \\
\text { efficiency and allows to } \\
\text { obtain high-purity } \\
\text { thearubigins }\end{array}$ & 2016 \\
\hline \multicolumn{5}{|l|}{ Theasinensins } \\
\hline KR101296418B1 & $\begin{array}{l}\text { South } \\
\text { Korea }\end{array}$ & & $\begin{array}{l}\text { The invention provides } \\
\text { food and beverage }\end{array}$ & 2005 \\
\hline
\end{tabular}


Table 4 (continued)

\begin{tabular}{|c|c|c|c|c|}
\hline Patent number & Country & Title & Brief description & Year \\
\hline & & $\begin{array}{l}\text { Lipase inhibitor } \\
\text { containing } \\
\text { theasinensins }\end{array}$ & $\begin{array}{l}\text { containing lipase } \\
\text { inhibitor based on a } \\
\text { mixture of theasinensins } \\
(\mathrm{A}, \mathrm{B} \text {, and } \mathrm{D})\end{array}$ & \\
\hline US20110064851A1 & USA & $\begin{array}{l}\text { Method of producing } \\
\text { fermented tea drink rich } \\
\text { in theaflavins }\end{array}$ & $\begin{array}{l}\text { The invention describes } \\
\text { the method for preparing } \\
\text { a fermented tea drink } \\
\text { rich in theaflavins and } \\
\text { theasinensins A and B, } \\
\text { characterized by little } \\
\text { bitterness and } \\
\text { astringency, } \\
\text { characterized by } \\
\text { excellent taste and } \\
\text { sweetness }\end{array}$ & 2009 \\
\hline JP2010138103A & Japan & $\begin{array}{l}\text { Method for producing } \\
\text { theasinensin }\end{array}$ & $\begin{array}{l}\text { The invention presents } \\
\text { method for producing } \\
\text { theasinensin by } \\
\text { oxidizing EGC and/or } \\
\text { EGCG in the presence } \\
\text { of a nonhomogeneous } \\
\text { catalyst and then } \\
\text { reducing the obtained } \\
\text { product. The method } \\
\text { provides higher } \\
\text { efficiency compared to } \\
\text { the conventional } \\
\text { methods }\end{array}$ & 2008 \\
\hline CN104621291A & China & $\begin{array}{l}\text { Method for extracting } \\
\text { and preparing } \\
\text { theasinensin from tea } \\
\text { leaves }\end{array}$ & $\begin{array}{l}\text { The invention discloses } \\
\text { solid-liquid extraction of } \\
\text { theasinensins from tea } \\
\text { leaves using acetone } \\
\text { solution }\end{array}$ & 2015 \\
\hline JP2010189321A & Japan & $\begin{array}{l}\text { Cholesterol-lowering } \\
\text { agent }\end{array}$ & $\begin{array}{l}\text { The invention describes } \\
\text { cholesterol-lowering } \\
\text { agent based on natural } \\
\text { products, which } \\
\text { contains theasinensin }\end{array}$ & 2009 \\
\hline
\end{tabular}




\section{References}

Alcazar A, Ballesteros O, Jurado JM (2007) Differentiation of green, white, black, oolong, and Puerh teas according to their free amino acids content. J Agric Food Chem 55:5960-5965

Anderson RA, Polansky MM (2002) Tea enhances insulin activity. J Agric Food Chem 50:7182-7186

Arent SM, Senso M, Golem DL (2010) The effects of theaflavin-enriched black tea extract on muscle soreness, oxidative stress, inflammation, and endocrine responses to acute anaerobic interval training: a randomized, double-blind, crossover study. J Int Soc Sport Nutr 7:11

Babich H, Gottesman RT, Liebling EJ, Schuck AG (2008) Theaflavin-3-Gallate and theaflavin-3'Gallate, polyphenols in black tea with prooxidant properties. Basic Clin Pharmacol Toxicol 103:66-74

Barua A (2008) Romancing the Camellia assamica (Assam and the story of tea). Assam Rev Tea News, $18-27$

Beecher GR (2003) Overview of dietary flavonoids: nomenclature, occurrence and intake. J Nutr 133:3248-3254

Betts JW, Kelly SM, Haswell SJ (2011) Antibacterial effects of theaflavin and synergy with epicatechin against clinical isolates of Acinetobacter baumannii and Stenotrophomonas maltophilia. Int J Antimicrob Agents 38(5):421-425

Catteral F, Copeland E, Clifford MN, Loannides C (1998) Contribution of theafulvins to the antimutagenicity of black tea: their mechanism of action. Mutagenesis 13:631-636

Chen J, Qin S, Xiao J, Tanigawa S, Uto T, Hashimoto F, Fujii M, Hou DX (2011) A genomewide microarray highlights the antiinflammatory genes targeted by oolong tea theasinensin $\mathrm{A}$ in macrophages. Nutr Cancer 63(7):1064-1073

Gosslau A, Jao DLE, Huang M-T, Ho C-T, Evans D, Rawson NE, Chen KY (2011) Effects of the black tea polyphenol theaflavin-2 on apoptotic and inflammatory pathways in vitro and in vivo. Mol Nutr Food Res 55(2):198-208

Halder B, Pramanick S, Mukhopadhyay S, Giri AK (2005) Inhibition of benzo[a]pyrene induced mutagenicity and genotoxicity by black tea polyphenols theaflavins and thearubigins in multiple test systems. Food Chem Toxic 43:591-597

Hashimoto F, Nonaka G, Nishioka I (1992) Tannins related compounds CXIV. Structure of novel fermentation products, theogallinin, theaflavonin and desgalloyl theaflavonin from black tea, and changes of tea leaf polyphenols during fermentation. Chem Pharm Bull 40:1383-1389

Haslam E (2003) Thoughts on thearubigins. Phytochemistry 64:61-73

He HF (2017) Research progress on theaflavins: efficacy, formation, and preparation. Food Nutr Res 61:1344521

Higdon JV, Frei B (2003) Tea catechins and polyphenols: health effects, metabolism, and antioxidant functions. Crit Rev Food Sci Nutr 43:89-143

Hisanaga A, Ishida H, Sakao K, Sogo T, Kumamoto T, Hashimoto F, Hou DX (2014) Anti-inflammatory activity and molecular mechanism of oolong tea theasinensin. Food Funct 5:1891-1897

Hosoda K, Wanf MF, Liao ML, Chuang CK, Iha M, Clevidence B, Yamamoto S (2003) Antihyperglycemic effect of oolong tea in type 2 diabetes. Diabetes Care 26:1714-1718

Hossain SJ, Kato H, Aoshima H (2002) Polyphenol induced inhibition of the response of $\mathrm{Na}+$ / glucose cotransporter expressed in xenopus oocytes. J Agric Food Chem 50:5215-5219

Hou DX, Masuzaki S, Tanigawa S, Hashimoto F, Chen J, Sogo T, Fujii M (2010) Oolong tea theasinensins attenuate cyclooxygenase-2 expression in lipopolysaccharide(LPS)-activated mouse macrophages: structure-activity relationship and molecular mechanisms. J Agric Food Chem 58:12735-12743

Hsu TF, Kusumoto A, Abe K, Hosoda K, Kiso Y, Wang MF, Yamamoto S (2006) Polyphenol enriched oolong tea increases fecal lipid excretion. Eur J Clin Nutr 60:1330-1336 
Hung WL, Yang G, Wang YC, Chiou YS, Tung YC, Yang MJ, Wang BN, Ho CT, Wang Y, Pan MH (2017) Protective effects of theasinensin A against carbon tetrachloride-induced liver injury in mice. Food Funct 8(9):3276-3287

Imran A, Arshad MU, Arshad MS, Imran M, Saeed F, Sohaib M (2018) Lipid peroxidation diminishing perspective of isolated theaflavins and thearubigins from black tea in arginine induced renal malfunctional rats. Lipid Health Dis 17(1):157

Isaacs CE, Xu W (2013) Theaflavin-3,3-digallate and lactic acid combinations reduce herpes simplex virus infectivity. Antimicrob Agents Chemother 57(8):3806-3814

Khan N, Mukhtar H (2007) Tea polyphenols for health promotion. Life Sci 81(7):519-533

Komatsu T, Nakamori M, Komatsu K, Hosoda K, Okamura M, Toyama K, Ishikura Y, Sakai T, Kunii D, Yamamoto S (2003) Oolong tea increases energy metabolism in Japanese females. J Med Investig 50:170-175

Lambert JD, Yang CS (2003) Cancer chemopreventive activity and bioavailability of tea and tea polyphenols. Mutation Res 523-524:201-208

Lee M-J, Lambert JD, Prabhu S, Meng X, Lu H, Maliakal P, Ho C-T, Yang CS (2004) Delivery of tea polyphenols to the oral cavity by green tea leaves and black tea extract. Cancer Epidemiol Biomark Prev 13:132-137

Maeda-Yamamoto M, Kawahara H, Tahara N, Tsuji K, Hara Y, Isemura M (1999) Effects of tea polyphenols on the invasion and matrix metalloproteinases activities of human fibrosarcoma HT1080 cells. J Agric Food Chem 47:2350-2354

Mahanta PK, Boruah SK, Boruah HK, Kalita JN (1993) Changes of polyphenol oxidase and peroxidase activities and pigment composition of some manufactured black teas (Camellia sinensis L.). J Agric Food Chem 41:272-276

Matsuo Y, Tanaka T, Kouno I (2006) A new mechanism for oxidation of epigallocatechin and production of benzotropolone pigments. Tetrahedron 62:4774-4783

Mulder TP, van Platerink CJ, Wijnand Schuyl PJ, van Amelsvoort JM (2001) Analysis of theaflavins in biological fluids using liquid chromatography-electrospray mass spectrometry. J Chromatogr Biomed Appl 760:271-279

Pan MH, Liang YC, Lin-Shiau SY, Zhu NQ, Ho CT, Lin JK (2000) Induction of apoptosis by the oolong tea polyphenol theasinensin A through cytochrome $\mathrm{c}$ release and activation of caspase- 9 and caspase-3 in human U937 cells. J Agric Food Chem 48:6337-6346

Pereira-Caro G, Moreno-Rojas JM, Brindani N, Del Rio D, Lean MEJ, Hara Y, Crozier A (2017) Bioavailability of black tea theaflavins: absorption, metabolism, and colonic catabolism. J Agric Food Chem 65:5365-5374

Rumpler W, Seale JJ, Clevidence B, Judd J, Wiley e, Yamamoto S, Komatsu T, Sawaki T, Ishikura Y, Hosoda K (2001) Oolong tea increases metabolic rate and fat oxidation in men. J Nutr 131:2848-2852

Sajilata MG, Bajaj PR, Singhal RS (2008) Tea polyphenols as nutraceuticals. Compr Rev Food Sci Food Saf 7(3):229-254

Shii T, Miyamoto M, Matsuo Y, Tanaka T, Kuono I (2011) Biomimetic one-pot preparation of a black tea polyphenol theasinensin A from epigallocatechin gallate by treatment with copper (II) chloride and ascorbic acid. Chem Pharm Bull 59(9):1183-1185

Sinha S, Ghaskadbi S (2013) Thearubigins rich black tea fraction reveals strong antioxidant activity. Int J Green Pharm 7(4):336-344

Tanaka T, Watarumi S, Matsuo Y, Kamei M, Kuono I (2003) Production of theasinensins A and D, epigallocatechin gallate dimers of black tea, by oxidation-reduction dismutation of dehydrotheasinensin A. Tetrahedron 59:7939-7947

Tchernof A, Despres JP (2013) Pathophysiology of human visceral obesity: an update. Physiol Rev 93:359-404

Tsai PH, Kan NB, Ho SC, Liu CC, Lin CC (2005) Effects of oolong tea supplementation on lipid peroxidation of athletes at rest and post-exhaustive exercise. J Food Sci 70:581-585

Wang W, Sun Y, Liu J, Wang J, Li Y, Li H, Zhang W, Liao H (2012) Protective effect of theaflavins on cadmium-induced testicular toxicity in male rats. Food Chem Toxicol 50(9):3243-3250 
Weerawatanakorn M, Lee Y-L, Tsai C-Y, Lai CS, Wan X, Ho CT, Li S, Pan MH (2015a) Protective effect of theaflavin-enriched black tea extracts against dimethylnitrosamine-induced liver fibrosis in rats. Food Funct 6:1832-1840

Weerawatanakorn M, Hung W-L, Pan M-H, Li S, Li D, Wan X, Ho C-T (2015b) Chemistry and health beneficial effects of oolong tea and theasinensins. Food Sci Human Wellness 4:133-146

Yang TT, Koo MW (1997) Hypercholesterolemic effects of Chinese tea. Pharmacol Res 35:505-512

Yang YC, Lu FH, Wu JS, Wu CH, Chang CJ (2004) The protective effect of habitual tea consumption on hypertension. Arch Int Med 164:1534-1540

Yao LH, Jiang YM, Caffin N, D’Arcy B, Datta N, Liu X, Singanusong R, Xu Y (2006) Phenolic compounds in tea from Australian supermarkets. Food Chem 96:614-620

Yi T, Zhu L, Peng W-L, He X-C, Chen H-L, Li J, Yu T, Liang Z-T, Zhao Z-Z, Chen H-B (2015) Comparison of ten major constituents in seven types of processed tea using HPLC-DAD-MS followed by principal component and hierarchical cluster analysis. LWT-Food Sci Technol 62:194-201

Zhang GY, Miura Y, Yagasaki K (2000) Induction of apoptosis and cell cycle arrest in cancer cells by in vivo metabolites of teas. Nutr Cancer 38:265-273 